\title{
Concurrencia de síndromes paraneoplásicos neurológicos, en paciente afecta de cáncer de mama y metástasis cerebral: revisión de la literatura
}

\author{
A. L. Moreno-Vega, S. Flores-Prieto, J. Fuentes-Pradera, I. Fernández-Cantón, J. M. Girón-Úbeda1, \\ E. Jiménez-Orozco
}

\section{Resumen}

Los Síndromes paraneoplásicos neurológicos son entidades complejas, de difícil diagnóstico, y que pueden afectar a cualquier parte del sistema nervioso. El descubrimiento de nuevos antígenos onconeuronales y su relación con las alteraciones inmunológicas asociadas están ayudando a un diagnóstico precoz. La asociación con el carcinoma de mama es infrecuente. Presentamos el caso de una paciente de 62 años, diagnosticada de carcinoma de mama izquierda, mastectomizada y tratada con quimioterapia adyuvante. Presentó recidiva, con metástasis cerebelosa resecada quirúrgicamente y tratada con radioterapia. Se complicó con cuadro miasteniforme de tipo Lambert-Eaton, disfunción autonómica y posterior encefalítis límbica con coma irreversible. La aplicación de los nuevos criterios diagnósticos, los descubrimientos moleculares y la realización de ensayos clínicos terapeúticos, podrían mejorar las expectativas en estas pacientes.

Palabras clave: Anticuerpos onconeuronales. Cáncer de mama. Encefalítis límbica. Quimioterapia. Síndrome Eaton-Lambert. Síndrome Paraneoplásico neurológico.

Oncología, 2006; 29 (2):76-80

\section{Summary}

Neurological paraneoplastic syndromes are complex entities of difficult diagnosis. They can locate in any part of the nervous system producing important neurological dysfunctions. The discovery of new specific anti-neuronal antibodies and their relation with the associated immunological alterations help to make an early diagnosis. Association with breast cancer is not frequent. We present the case of a 62-year old patient with left breast carcinoma that had been treated by mastectomy and adjuvant chemotherapy one year before. She relapsed with cerebellum metastases and was treated by surgery and radiotherapy. The picture was complicated with a Lambert-Eaton-like myasthenic syndrome, neuroplastic sensory neuronopathy, limbic encephalitis and irreversible coma. The application of new diagnostic criteria, the molecular discoveries and the performance of therapeutic clinical trials could better the life expectancy of these patients.

Key words: Onconeuronal antibodies. Breast cancer. Limbic encephalitis. Chemotherapy. Lambert-Eaton syndrome. Neurological paraneoplastic syndrome

Unidad de Oncología Médica

${ }^{1}$ Servicio de Neurología

Hospital de Jerez (Cádiz)

Recibido: 30.08 .05

Aceptado: 22.12.05 


\section{Introducción}

Los síndromes paraneoplásicos neurológicos (SPN) definen a una serie de alteraciones del sistema nervioso asociadas a neoplasias, pero no como resultado de metástasis, complicaciones (infecciones, trastornos cerebro-vasculares, alteraciones metabólicas o nutricionales) o efectos secundarios del tratamiento del cáncer. Pueden preceder al diagnóstico de éstas en más de la mitad de los $\operatorname{casos}^{1-3}$. Los recientes descubrimientos de antígenos onconeuronales están ayudándonos al diagnóstico más precoz de estos SPN, considerados como resultado de alteraciones inmunológicas asociadas a determinados anticuerpos específicos, pudiendo definirlos como bien caracterizados ${ }^{1-6}$. Su dificultad diagnóstica es mayor en casos como el que presentamos, con el antecedente de enfermedad tumoral metastásica en sistema nervioso central, las posibles secuelas de cirugía intracraneal en región cerebelosa y del tratamiento antineoplásico. Los SPN pueden afectar a cualquier parte del sistema nervioso desde la corteza cerebral hasta la unión neuromuscular y músculo, llegando a ser más incapacitantes que la propia neoplasia primaria. La asociación con el cáncer de mama es infrecuente (según algunos autores de un $8 \%)^{3-5}$. No obstante, la ausencia de anticuerpos detectables en suero y la desconocida fisiopatología de estos cuadros en tumores como el cáncer de mama, hacen frustrante el manejo de estas pacientes, sobre todo cuando debemos abordar terapéuticamente una situación complicada, como es la enfermedad metastásica cerebral por cáncer de mama ${ }^{4-9}$.

\section{Caso clínico}

Paciente de 62 años al diagnostico, sin antecedentes previos de interés, no diabética ni hipertensa, obesa y menopaúsica diez años antes. Diagnosticada de carcinoma de mama izquierda en marzo de 2002 , tras la realización de una mastectomía radical izquierda y linfadenectomía axilar ipsilateral. El resultado histológico fue de carcinoma ductal infiltrante de mama, de $14 \mathrm{~mm}$, con afectación metastásica en 2 de 7 ganglios axilares aislados, con permeación de vasos capsulares y extracapsulares; mostrando el estudio inmunohistoquímico receptores estrogénicos levemente positivos y de progesterona negativos. Se estadificó entonces como pT1cN1biM0 (estadio IIA). Realizó tratamiento poliquimioterápico con esquema de 5-fluoracilo, ciclofosfamida y 4-epirrubicina (FEC), completando seis ciclos y posteriormente continuó con hormonoterapia (tamoxifeno $20 \mathrm{mg}$ diarios). En febrero de 2003 comenzó con cefaleas holocraneales, autolimitadas y mareos. No presentaba alteraciones neurológicas a la exploración, ni otra sintomatología acompañante. Se le realizó tomografía axial computerizada (TAC) craneal, evidenciando una lesión cerebelosa intraaxial-basal derecha, confirmada mediante imágenes de resonancia magnética nuclear (RMN) cerebral, de un tamaño de 4 centímetros y de componente quístico, sin edema perilesional y con captación patológica de gadolinio. Se realizó estudio de extensión, con TAC completo de tórax-abdomen, mamografía y gammagrafía ósea sin evidencia de enfermedad; los valores de hematimetría, función renal y hepática eran normales, con marcadores tumorales normales. Se decidió realizar craneotomía con exéresis completa de la lesión descrita, siendo la histología diagnóstica de metástasis de carcinoma de mama, con bordes libres de enfermedad. A las dos semanas de la intervención, comienza a referir dolor de características musculares en miembros inferiores y cadera, con dificultad progresiva para la marcha, fatigabilidad fácil e imposibilidad para incorporarse desde la cama, con parestesias importantes. Presentó cambios en el comportamiento, pérdida de memoria y episodios de confusión. A la exploración se apreciaba ataxia, con leve disminución de fuerza muscular en miembros inferiores, sobre todo proximal, sin alteración de reflejos osteotendinosos ni de la sensibilidad, pares craneales normales y ausencia de nistagmo. Iniciamos tratamiento analgésico, segunda línea de hormonoterapia con inhibidor de aromatasa y se planificó radioterapia craneal. La sintomatología cedió parcialmente, comenzando con episodios de rubefacción, sudoración profusa y estreñimiento. Se realizó nuevo estudio mediante RMN cerebral y columna, no evidenciándose lesiones medulares, y tan solo cambios postquirúrgicos en región basal de cerebelo derecho y calota adyacente, con mínimo realce no patológico tras administración de gadolinio (Figura 1). Inició tratamiento radioterápico holocraneal complementario a la cirugía. Los marcadores tumorales comenzaron a elevarse discretamente, con antígeno carcino- 


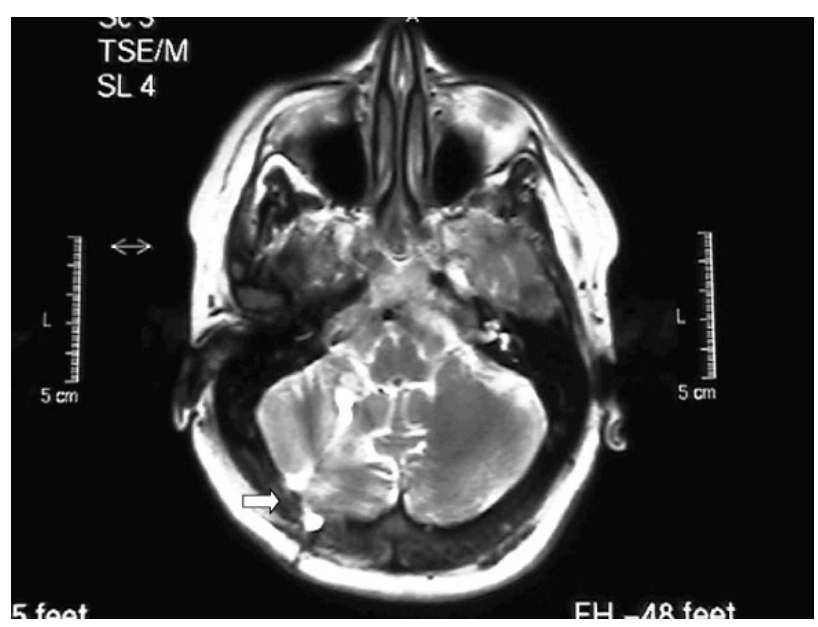

Figura 1. RMN cerebral con contraste (gadolinio): cambios postquirúrgicos en región basal de cerebelo derecho y calota adyacente, con mínimo realce no patológico tras administración del contraste.

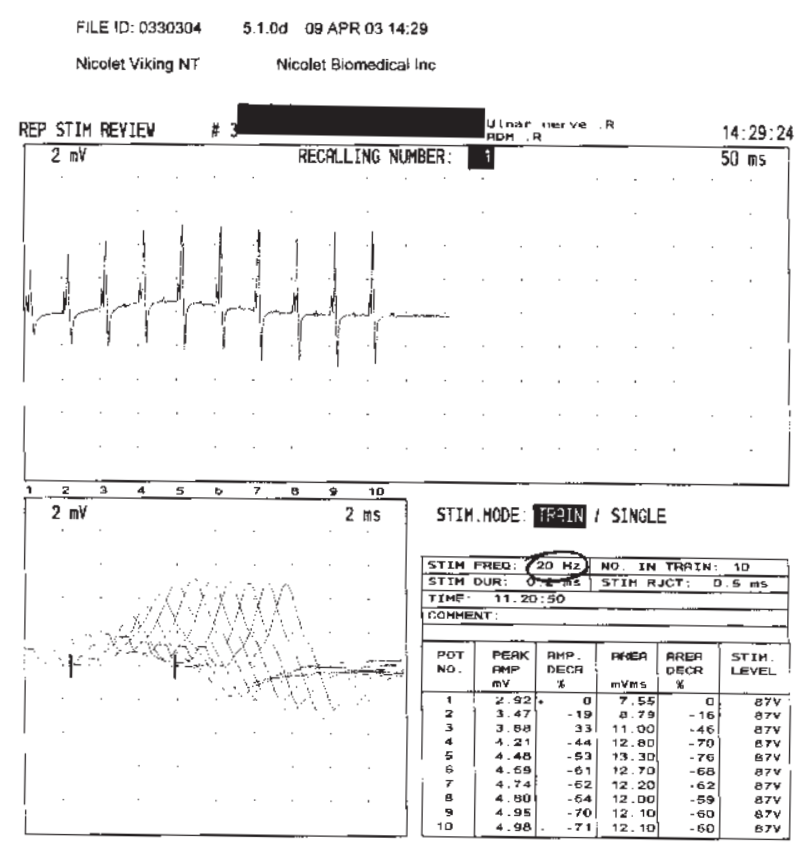

Figura 2. El estudio neurofisiológico mostró un evidente patrón miasteniforme de actividad repetitiva, concordante con síndrome de Eaton-Lambert, con ausencia de actividad denervativa, proceso miopático o medular.

embrionario (CEA) normal y CA15,3 de 29,7 $\mathrm{UI} / \mathrm{ml}$; presentando elevación de láctico-dehidrogenasa $(\mathrm{LDH})$ superior a $530 \mathrm{UI} / \mathrm{l}$, con enzimas musculares normales, proteínas totales normales. El estudio neurofisiológico mostró un evidente patrón miasteniforme de actividad repetitiva (Figura 2), concordante con síndrome de Lambert-Eaton, con ausencia de actividad denervativa, proceso miopático o medular. Comenzamos tratamiento esteroideo a dosis altas de dexametaxona y programamos tratamiento con plasmaféresis semanal. Sin embargo, la paciente continuó con clínica progresiva de cefalea occipital, mayor astenia, debilidad muscular, ptosis bilateral, estreñimiento severo por paresia intestinal, desorientación temporo-espacial y brote psicótico, sin respuesta a primera plasmaféresis. Repetimos RMN cerebral que no mostró cambios parenquimatosos, ni en zona quirúrgica. Se realizó punción lumbar que sólo evidenció hiperproteinorraquia leve. Posteriormente sufrió mayor deterioro de funciones superiores con desorientación temporo-espacial completa y alteraciones psicóticas, disartria y bradipsiquia, hasta quedar en situación de coma. Los marcadores tumorales continuaron elevándose con CA 15,3 de 37,2 UI/ml, disminuyendo la $\mathrm{LDH}$ a valores normales. El estudio inmunológico reveló una elevación de anticuerpos antineutrófilos propios de las enfermedades autoinmunes (ANCAp) inespecífica (confirmada con técnica de PCR); negatividad para el anticuerpo anti-receptor de acetilcolina, con positividad para los anticuerpos contra los canales de calcio; los anticuerpos antiHu y antiYo (séricos y en líquido cefalorraquídeo) fueron negativos; la determinación de proteinas Ma resultó negativa, la serología vírica fue también negativa. Se desestimó tratamiento quimioterápico con taxanos y la paciente falleció en mayo de 2003, tras varios días en coma.

\section{Discusión}

Los SPN aparecen bien caracterizados en su presentación clínica, sin embargo tienen una gran complejidad diagnóstica. Precisan un descarte de otros procesos asociados a la enfermedad tumoral, como infecciones del sistema nervioso central, efectos neurotóxicos de la quimioterapia, accidentes cerebrovasculares o toxicidad de la radioterapia holocraneal ${ }^{1-5}$. La sintomatología pueda mantenerse solapada cuando concurre con lesiones metastásicas, siendo más evidente tras la exéresis de éstas ${ }^{10}$. La existencia de un cuadro miasteniforme tipo Lambert-Eaton, puede confirmarse por el estudio electromiográ- 
fico compatible (que permite descartar una causa secundaria a citostáticos o infiltración metastásica $)^{11}$ y por la existencia de anticuerpos contra canales del calcio. Éste puede responder a tratamiento de recambio plasmático, a diferencia de los SPN del sistema nervioso central como la encefalomielitis paraneoplásica. El diagnóstico de una posible encefalitis límbica o encefalomielitis es fundamentalmente clínico (pérdida de memoria, desorientación, alucinaciones, confusión, depresión o psicosis e incluso convulsiones, evolucionando a un gran deterioro intelectual o coma, aunque a veces puede estabilizarse durante meses). En los casos de disfunción autonómica suele manifestarse con episodios de hipotensión ortostática y anhidrosis-sudoraciones profusas, boca seca, temblor o parestesias, acompañados de estreñimiento por pseudo-obstrucción intestinal y retención urinaria. Además, debe apoyarse con la determinación de autoanticuerpos, estudio de imagen y en determinados casos la biopsia ${ }^{1-4,12}$. La mayoría de pacientes con cuadros de encefalomielitis paraneoplásica están asociados al antígeno $\mathrm{Hu}$, y en menor medida se descubre asociación con antígenos onconeuronales como la familia de proteinas Ma. El anticuerpo anti-Hu reconoce un grupo de antígenos $\mathrm{Hu}$ (ANNA-1 o anti-neuronal nuclear antibody-1) con peso molecular de $35 \mathrm{kDa}$ y que pueden expresarse en el núcleo de neuronas del SNC y periférico infantil o adulto, en células tumorales de origen neuroblástico y neuroectodérmico de diferenciación neuroendocrina y en las células tumorales de los carcinomas pulmonares de tipo oat cell ${ }^{1-5}, 12,13$. En casi el $80 \%$ de ocasiones el anti-Hu aparece en pacientes afectos de oat cell. El $20 \%$ restante en otros carcinomas pulmonares, de mama, de próstata, seminomas, neuroblastomas o adenocarcinomas colorrectales ${ }^{1-3}$. El problema diagnóstico se incrementa cuando no disponemos de apoyo serológico, ya que los cánceres de mama y ovario que cursan con SPN de este tipo se asocian en menos de un $36 \%$ de los casos con los anticuerpos conocidos (anti Hu ó anti Yo), quizás por la presencia de anticuerpos dirigidos a otros epítopos atípicos o no detectables ${ }^{3-4,14}$. En otras ocasiones se describe presencia de otros anticuerpos desconocidos hasta en un $32 \%$ de los casos publicados y no identificables en el $16 \%{ }^{14}$. Pueden determinarse otros anticuerpos antineuronales en suero, como las proteínas Ma, detectadas en otros cuadros de encefalitis límbica asociados a tumores germinales o testi- culares $^{1-3,15}$. La presencia de anticuerpos antineuronales suelen ocurrir en determinados SPN, cuando éstos se asocian con el tipo de tumor mas frecuente o característico para dicho síndrome. No obstante, en raras ocasiones el tumor responsable de un SPN asociado a un determinado anticuerpo antineuronal es distinto al tumor que cabría esperar para ese anticuerpo, pudiendo tratarse de un segundo tumor primario oculto (por ejemplo, la frecuente asociación con el Síndrome de Lambert-Eaton, de un cáncer de pulmón $)^{1-3}$. El concepto de heterogeneidad clínicoinmunológica, define la asociación de diferentes anticuerpos a un mismo síndrome neurológico o al contrario, la asociación de varios síndromes a un mismo anticuerpo (como en el caso de anticuerpos anti-Hu en pacientes con múltiples síntomas de encefalomielitis y neuropatía sensitiva por afectación de ganglio raquídeo posterior), siendo la asociación Lambert-Eaton y anticuerpos anticanales de calcio dependientes de voltaje, la mas constante ${ }^{1-4}$. En otros casos pueden ocurrir SPN sin una respuesta inmunológica detectable, o incluso un determinado síndrome puede asociarse a varios anticuerpos, como por ejemplo la degeneración cerebelosa con anticuerpos anti-Hu, anti.Yo, anti-Tr y anti-Ma, o la encefalitis límbica con anti-Hu y anti-Ta(Ma2) ${ }^{1,2}$. La RMN cerebral es de escasa ayuda como apoyo diagnóstico, aunque se describe en algunos pacientes afectos de encefalitis límbica, la presencia de alteraciones de la señal en secuencias T2 en la región medial de los lóbulos temporales ${ }^{1,16}$ El diagnóstico definitivo de un SPN de sistema nervioso central requiere biopsia cerebral, por la presencia de infiltrados linfocitarios, activación microglial focal e imágenes de neuronofagia en el complejo hipocampoamigdala y corteza cerebral singular y orbitaria en los casos de encefalitis límbica ${ }^{2}$. En el caso de disfunción autonómica, se describen infiltrados linfocitarios, pérdida neuronal y gliosis reactiva en el SNC y en los ganglios paravertebrales ${ }^{2}$.

Creemos que la verdadera dificultad del caso se encontraba en la diferenciación entre posible recidiva de la enfermedad metastásica cerebral previamente conocida y la coexistencia de sintomatología atribuible a un cuadro paraneoplásico múltiple. La negativa de la familia a la realización de la autopsia impidió confirmar el diagnóstico. En cualquier caso, el diagnóstico precoz de ambas situaciones puede ser de gran valor, si tenemos en cuenta un posi- 
ble mayor beneficio clínico de estas pacientes al ser tratadas con quimioterapia (se describen repuestas clínicas con mejoría del déficit neurológico hasta en el $30 \%$ de los casos) o plasmaféresis ${ }^{8,9,14,17,18}$. Se desconoce si en estos casos la presencia de SPN supone una evidencia de enfermedad "no evidenciable", como se describe en términos anglosajones (estadio IV NED). No encontramos en la literatura revisada evidencia científica suficiente para plantear tratamiento quimioterápico empíricamente en estas situaciones sin enfermedad medible, aunque se describan en algunos casos mejorías clínicas tras instaurar tratamiento $8,9,17$. El tratamiento esteroideo en esta paciente no aportó ningún beneficio en la mala evolución clínica. Creemos, al igual que otros autores, que no disponemos en el momento actual de tratamiento eficaz para resolver cuadros complejos de estas características, siendo difícil plantear ensayos clínicos randomizados en este tipo de pacientes tan heterogéneo.

Correspondencia:

Dr. A. L. Moreno Vega

Pasaje Petunia, 6

E-41089 Sevilla

bertsand@terra.es

oncojerez@saludalia.com

\section{Bibliografía}

1. Dalmau J. Síndromes neurológicos paraneoplásicos: desde el diagnóstico de exclusión a la utilización de marcadores inmunológicos y moleculares. Neurología, 2000;15(3): 114-126.

2. Ferrer I. Patología de los síndromes paraneoplásicos del sistema nervioso central, periférico y músculo. Rev Neurol, 2000;31(12):1228-36.

3. Gultekin SH, Myrna R. Rosenfeld MR, Voltz R, Eichen J, Jerome B. Posner JB, Dalmau J. Paraneoplastic limbic encephalitis: neurological symptoms, immunological findings and tumour association in 50 patients. Brain, 2000;123(7): 1481-1494.

4. Graus F, Delattre JY, Antoine JC, Dalmau J, Giometto B, Grisld W, et al. Recommended diagnostic criteria for para- neoplastic neurological syndromes. Journal of Neurology Neurosurgery and Psychiatry 2004;75:1135-1140

5. Sutton I, Winer JB. The inmunopathogenesis of paraneoplastic neurological syndromes. Clin Sci 2002;102(5):47586.

6. Iglesias L, Chinchón I, Ferreras G, Moreno AL, Sáez C, López JL. Tumores cerebrales. En Cortés H, Diaz E, García J, Germá JR, Guillém V, López JJ, Moreno JA, Pérez G, eds. Oncología Médica, Madrid 1999:11591204.

7. Das A, Hochberg FH, McNelis S. A review of the therapy of paraneoplastic neurologic syndrom. J Neurooncol 1999;41(2):181-94.

8. Blaes F. Immunotherapeutic approaches to paraneoplastic neurological disorders. Expert Opin Investig Drugs, 2000; 9(4):727-33.

9. Krarup C, Crone C. Neurophysiological studies in malignant disease with particular reference to involvement of perpheral nerves. Neurol, 2002;249(6):651-61.

10. Vecht CJ. Management of brain metastases. In: Evidencebased Oncology. Williams C ed. BMJ Publishing Group. London, 2003:574-8

11. Dropcho EJ. Update on paraneoplastic syndromes. Curr Opin Neurol, 2005 ;18(3):331-6.

12. Bechich S, Graus F, Arboix A, Isidro A, Marti M, Rosell F. Anti-Hu-associated paraneoplastic sensory neuropathy and breast cancer. J Neurol 2000;247(7):552-3.

13. Honnorat J, Cartalat-Carel S. Advances in paraneoplastic neurological syndromes. Curr Opin Oncol, 2004;16(6): 614-20.

14. Altaha R, Abraham J. Paraneoplastic neurologic syndrome associated with occult breast cancer: a case report and review of literature. Breast J. 2003;9(5):417-9.

15. Sutton I, Winer J, Rowlands D, Dalmau J. Limbic encephalitis and antibodies to Ma2: a paraneoplastic presentation of breast cancer. J Neurol Neurosurg psychiatriy 2000;69: 266-8.

16. Glantz MJ, Biran H, Myers ME, Gockerman JP, Friedberg $\mathrm{MH}$. The radiographic diagnosis and treatment of paraneoplastic central nervous system disease. Cancer 1994,73(1): 168-75.

17. Keime-Guibert F, Graus F, Fleury A, Rene R, Honnorat J, Broet $\mathrm{P}$, et al. Treatment of paraneoplastic neurological syndromes with antineuronal antibodies (Anti HU, anti Yo) with a combination of immunoglobulins, cyclophosphamide, and methylprednisolone. Neurol Neurosurg Psychiatry, 2000;68(4):479-82.

18. Graus F, Vega F, Delattre JY, Bonaventura I, Rene R, Arbaiza D, To E. Plasmapheresis and antineoplastic treatment in CNS paraneoplastic syndromes with antineuronal antibodies. Neurology 1992;42(3):536-40. 